\title{
Risk of pneumonia and pneumococcal disease in people with severe mental illness: English record linkage studies
}

\author{
Olena O Seminog, Michael J Goldacre
}

\begin{abstract}
- Additional supplementary files are published online only. To view these files please visit the journal online (http://dx. doi.org/10.1136/thoraxjn-2012-202480).

Unit of Health-Care Epidemiology, Department of Public Health, University of Oxford, Oxford, UK
\end{abstract}

\section{Correspondence to} Professor Michael J Goldacre, Unit of Health-Care Epidemiology, Department of Public Health, University of Oxford, Old Road Campus, Old Road, Oxford OX3 7LF,

UK;

michael.goldacre@dph.ox.ac.uk

Received 26 July 2012

Revised 15 November 2012

Accepted 22 November 2012

Published Online First

15 December 2012

\begin{abstract}
Background People with severe mental illness have a higher risk than others of some physical diseases. The risk of pneumococcal disease in people with mental disorders is unknown. This is potentially important because vaccines against the pneumococcus are available.

Methods We used two datasets of linked hospital admission and death records, the Oxford Record Linkage Study and all-England linked Hospital Episode Statistics, to estimate the risk of lobar pneumonia and other pneumococcal disease (here, all collectively termed pneumococcal disease) in people hospitalised with schizophrenia, bipolar disorder, depression or anxiety. We compared rates of pneumococcal disease in each cohort with rates in a comparison cohort of people without a record of hospitalisation for these psychiatric disorders.
\end{abstract}

Findings The risk of pneumococcal disease in each psychiatric group was significantly high in both datasets. In the English national dataset (spanning 1999-2011), the risk of pneumococcal disease in people hospitalised with schizophrenia, bipolar disorder, depression or anxiety was, respectively, $2.3(95 \% \mathrm{Cl} 2.2$ to 2.4$), 2.3$ (2.2 to 2.3 ), 2.1 (2.0 to 2.1 ) and 2.2 (2.1 to 2.2 ). The risk remained high for years after discharge, suggesting an association with the psychiatric disorder rather than with the event of hospitalisation.

Conclusions Severe mental illness is a risk factor for lobar pneumonia, pneumococcal pneumonia, pneumococcal septicaemia and meningitis. Possible explanations for the elevated risk include factors relating to lifestyle and health-risk activities. If our findings are replicated elsewhere, there would be a case for considering routine pneumococcal immunisation for people with severe mental illness.

\section{INTRODUCTION}

There is evidence that people with psychiatric disorders are at increased risk of common infectious diseases, ${ }^{1}$ but to the best of our knowledge, there have been no large studies of the risk of pneumococcal disease in people with severe mental illness. Pneumococcal disease is the term used to describe infections caused by the bacterium Streptococcus pneumoniae when the pathogen is detected in normally sterile body fluids. Streptococcus pneumoniae is the main cause of community-acquired pneumonia, bacteraemia and bacterial meningitis in adults in developed countries. ${ }^{2-4}$ Identification of people

\section{Key messages}

What is the key question?

- Is severe mental illness a risk factor for pneumococcal disease?

\section{What is the bottom line?}

- People with severe mental illness are at higher risk than others of pneumococcal disease, but are not yet recognised as a high-risk group in current immunisation policies.

\section{Why read on?}

- This is a new risk factor for pneumococcal disease. As we discuss, the risk is likely to be mediated by lifestyle factors associated with severe mental illness. Consideration should be given to routinely offering pneumococcal vaccine to people with severe mental illness.

with an excess risk of pneumococcal disease is important because vaccines against the pneumococcus are now available. Immunisation for high-risk groups is routinely offered.

Current immunisation guidelines in the UK and the USA are designed to protect those at elevated risk of pneumococcal disease, including infants, adults aged 65 and over, and people with selected medical conditions. ${ }^{5} 6$ However, patients with mental disorders are not specifically covered by the current guidelines. We used routine datasets of hospital admission and mortality data, enhanced by record linkage, to study the risk of pneumococcal disease in people admitted to hospital for schizophrenia, bipolar disorder, depression or anxiety.

\section{METHODS}

We analysed records from an English national dataset of linked Hospital Episode Statistics and mortality statistics (LHES), and from the Oxford Record Linkage Study (ORLS). ${ }^{7} 8$ Both datasets comprise statistical records of all hospital admissions, and day cases, for all patients admitted for National Health Service (NHS) care in their respective geographical areas. The ORLS covers the former Oxford NHS region from 1963 to February 2011. The all-England dataset runs from 1999 to February 2011. The analysis of the ORLS dataset was undertaken in two periods, 1963-1998 (ORLS1) and 1999-2011 
(ORLS2). Cross linkage between the pre-1999 and post-1999 data is not possible. Fortuitously for the current study, routine pneumococcal immunisation for susceptible groups of people became reasonably widespread in England from about 1999. We were interested in risk in pre-immunisation and post-immunisation populations, and in studying two available datasets, which is why we used the longstanding ORLS and the national English data.

\section{Population}

The ORLS commenced in part of the former NHS region of Oxford (covering about 850000 people) and gradually expanded over time until it covered the whole region (from 1987) with a population of about 2.5 million. It covers a relatively affluent part of England and comprises towns, but no large cities (the city of Oxford had a population of 134000 at the 2001 census), and rural populations. The great majority of this population, particularly in the early years of the ORLS, were born in southern England. It is demographically more homogeneous than England as a whole. England has a population of about 52 million.

\section{Exclusion and inclusion criteria}

We excluded anyone aged under 15 years. We assembled statistical cohorts of the records of people with day case care or hospital admission for schizophrenia, defined as International Classification of Diseases, 10th revision (ICD-10) codes F20F21, bipolar disorder (F31, F32.3, F33.3, F39), depression (F32.0-F32.2, F32.8, F32.9, F33.0-F33.2) and phobic anxiety disorders (F41). We termed these the 'exposure' conditions. The 'outcomes' of interest were lobar pneumonia, without further specification (J18.1), which is considered to be generally caused by Streptococcus pneumoniae, ${ }^{3}$ pneumonia specified as $S$ pneumoniae (J13), septicaemia due to $S$ pneumoniae (A40.3) and pneumococcal meningitis (G00.1). Although lobar pneumonia without further specification can only be considered 'presumed' pneumococcal disease, for simplicity we refer to these conditions collectively as pneumococcal disease. The same codes have been used by other researchers in studies of pneumococcal disease. ${ }^{9}$ The corresponding diagnostic codes were selected from the seventh, eighth and ninth revisions of ICD. There was no separate code for pneumococcal pneumonia in the earlier versions of ICD because pneumococcal pneumonia and lobar pneumonia 'organism unspecified' had the same ICD code (481 in ICD-9 and ICD-8, 490 in ICD-7).

\section{Analytical design}

The same methods were used for each mental illness and are described for schizophrenia. The schizophrenia cohort was constructed by identifying the first record of hospital care for schizophrenia for each individual, recorded as the principal diagnostic reason for admission or day care. We excluded those with a record of pneumococcal disease before or at the same time as admission for schizophrenia. We did this, first, to ensure as best as possible the likely temporal relationship between prior mental illness and subsequent pneumococcal infection; and second, to avoid the 'surveillance bias' that people might have been diagnosed with mental disease as a result of having in-hospital care for pneumococcal disease. We included subsequent pneumococcal disease, as an outcome, when recorded in any diagnostic position. In a sensitivity analysis, we varied the selection criteria (eg, pneumococcal disease in any diagnostic position or as the principal diagnosis) to check whether our choices made any appreciable difference to the results. They did not.
We constructed a comparison cohort using hospital controls and the standard epidemiological practice of selecting a wide range of conditions. The majority were minor medical or surgical conditions or injuries (see footnotes to table 2). As a check, for each condition in the reference cohort we estimated the risk of pneumococcal disease to ensure that the reference cohort did not include conditions with atypically high or low rates. In line with our work elsewhere, we term this the reference cohort. ${ }^{10}$ Anyone with one of the mental illnesses and a reference cohort condition was assigned only to the mental illness cohort. All patients aged 15 and over who were eligible for the reference cohort were included. During analysis, patients in the exposure and reference cohorts were stratified by age (in 5-year groups), sex, district of residence in ORLS (eight districts) and region of residence in LHES (of which there are nine in England), calendar year of first hospitalisation, and Index of Multiple Deprivation quintile (only available in LHES) to ensure that, following stratified analysis (see below), the results comparing the cohorts were equivalent in these respects. The assumptions made in the design are that the rates of pneumococcal disease in the reference cohort are representative of the general population while allowing for inward and outward migration (data on migration of individuals were not available).

\section{Statistical methods}

Rates of pneumococcal disease were calculated using personyears. The 'date of entry' into either the schizophrenia or reference cohort was that of first admission for schizophrenia or the reference condition. The 'date of exit' was that of first admission for pneumococcal disease, death or the end of the data-file (December 1998 for ORLS1, February 2011 for ORLS2 and LHES), whichever was the earliest. In comparing the schizophrenia cohort with the reference cohort, we first calculated the rates stratified, and then standardised, according to age at entry to the cohort (in 5-year age groups) and by the other stratification variables described above.

We applied the indirect method of standardisation, using the schizophrenia cohort and the reference cohort, combined, as the standard population, and applied the stratum-specific rates in the combined population to the number of people in each stratum in, first, the schizophrenia cohort, and second, the reference cohort. We calculated the ratio of the rate of pneumococcal disease in the schizophrenia cohort relative to that in the reference cohort, using the formula $\left(\mathrm{O}^{\mathrm{s}} / \mathrm{E}^{\mathrm{s}}\right)$ divided by $\left(\mathrm{O}^{\mathrm{r}} / \mathrm{E}^{\mathrm{r}}\right)$, where $\mathrm{O}^{\mathrm{s}}$ and $\mathrm{E}^{\mathrm{s}}$ are the observed and expected numbers of pneumococcal disease in the schizophrenia cohort and $\mathrm{O}^{\mathrm{r}}$ and $\mathrm{E}^{\mathrm{r}}$ are the equivalents in the reference cohort. We calculated the $95 \% \mathrm{CI}$ for the rate ratio (RR) and $\chi^{2}$ statistics for its significance, with continuity corrections for small numbers, as described elsewhere. $^{11}$

\section{RESULTS}

In the England dataset there were 85769 people with schizophrenia, 83 951with bipolar disorder, 138963 with depression and 58816 with anxiety. Basic population characteristics are shown in table 1 . In the ORLS2 dataset there were 3616 people with schizophrenia, 3699 with bipolar disorder, 8252 people with depression, and 1970 people with anxiety. The corresponding figures in ORLS1 were 5451 people with schizophrenia, 8193 with bipolar disorder, 20842 with depression and 16538 with anxiety. The great majority of the pneumococcal disease outcomes were lobar pneumonia.

Tables 2 and 3 show the RRs for the association between the mental disorders and pneumococcal disease in the three 
Table 1 Age and sex distribution of people admitted to hospital with mental conditions: number of people, percentage who were men, and ratio of people in the reference cohort in each stratum for each case in the mental illness cohort in the same stratum *, England

\begin{tabular}{|c|c|c|c|c|c|c|c|c|c|c|c|c|}
\hline \multirow[b]{2}{*}{$\begin{array}{l}\text { Age } \\
\text { group } \\
\text { (years) }\end{array}$} & \multicolumn{3}{|l|}{ Schizophrenia } & \multicolumn{3}{|l|}{ Bipolar disorder } & \multicolumn{3}{|l|}{ Depression } & \multicolumn{3}{|l|}{ Anxiety } \\
\hline & $\begin{array}{l}N \text { in exposure } \\
\text { cohort } \\
\text { (\% men) }\end{array}$ & $\begin{array}{l}\% \text { of } \\
\text { total }\end{array}$ & $\begin{array}{l}\text { Stratum } \\
\text { ratio** }\end{array}$ & $\begin{array}{l}\mathrm{N} \text { in exposure } \\
\text { cohort } \\
(\% \text { men })\end{array}$ & $\begin{array}{l}\% \text { of } \\
\text { total }\end{array}$ & $\begin{array}{l}\text { Stratum } \\
\text { ratio** }\end{array}$ & $\begin{array}{l}N \text { in exposure } \\
\text { cohort } \\
\text { (\% men) }\end{array}$ & $\begin{array}{l}\% \text { of } \\
\text { total }\end{array}$ & $\begin{array}{l}\text { Stratum } \\
\text { ratio* }\end{array}$ & $\begin{array}{l}N \text { in exposure } \\
\text { cohort } \\
\text { (\% men) }\end{array}$ & $\begin{array}{l}\% \text { of } \\
\text { total }\end{array}$ & $\begin{array}{l}\text { Stratum } \\
\text { ratio** }\end{array}$ \\
\hline $15-24$ & $13490(78.5)$ & 16 & 60 & 6099 (49.7) & 8 & 133 & $12835(43.0)$ & 9 & 62 & 5291 (39.3) & 9 & 153 \\
\hline $25-34$ & $21832(73.1)$ & 25 & 42 & $13205(44.0)$ & 15 & 69 & 20847 (45.9) & 15 & 43 & 7034 (43.4) & 12 & 129 \\
\hline $35-44$ & $19771(64.0)$ & 23 & 47 & $16748(40.2)$ & 20 & 55 & 25477 (44.8) & 19 & 35 & 9164 (41.6) & 16 & 100 \\
\hline $45-59$ & $17987(55.4)$ & 21 & 76 & $21353(38.4)$ & 26 & 64 & $27778(45.4)$ & 20 & 47 & 12629 (39.6) & 21 & 107 \\
\hline $60-74$ & 9085 (41.4) & 11 & 153 & $16249(36.5)$ & 19 & 86 & 24099 (39.9) & 17 & 56 & $12233(32.9)$ & 21 & 113 \\
\hline $75+$ & 3604 (25.5) & 4 & 185 & $10297(29.4)$ & 12 & 65 & 27927 (32.3) & 20 & 23 & $12465(23.2)$ & 21 & 53 \\
\hline Total & $85769(62.8)$ & 100 & 74 & $83951(39.0)$ & 100 & 75 & $138963(41.5)$ & 100 & 44 & $58816(35.6)$ & 100 & 106 \\
\hline
\end{tabular}

The equivalent data are not shown for people in the ORLS1 and ORLS2 datasets, and are available from the authors.

*In the analysis we included all people eligible to be in each stratum in the reference cohort in calculating the stratum-specific 'expected' numbers of people with subsequent pneumococcal disease (there was no benefit in excluding people to get equal numbers in each stratum). For example, in the schizophrenia analysis, there were 809400 people in the reference cohort aged 15-24 compared with 13490 people in the schizophrenia cohort.

datasets. In the England and ORLS2 datasets there was about a twofold elevation of risk of pneumococcal disease in each of the four psychiatric groups: for example, the RRs in England were 2.3 in people with schizophrenia and bipolar disorder, 2.1 for depression and 2.2 for anxiety (all significant, see table 2 for CIs). When the analysis was restricted to people aged under 60 years, the association strengthened: for example, the RRs in England were 2.8 in people with schizophrenia, 2.6 for bipolar disorder, 2.9 for depression and 2.8 for anxiety (all significant, see table 3 ). RRs in the ORLS1 cohorts were also all high, though less elevated than those in the England and ORLS2 cohorts (tables 2 and 3). RRs were very similar for lobar pneumonia and for pneumococcal pneumonia specified as such (tables 2 and 3 ).

Cases of pneumococcal septicaemia and meningitis were uncommon (72 and 24 cases, respectively, across the psychiatric cohorts in the all-England analysis), but, when numbers were large enough to make judgements, people in the psychiatric cohorts had an elevated risk of both. Because of small numbers, we combined the four psychiatric disorders: overall, the RR for pneumococcal septicaemia in people with severe mental disorder was 1.9 (95\% CI 1.5 to 2.4 ) and the RR for pneumococcal meningitis was 1.8 (95\% CI 1.1 to 2.7$)$.

Table 2 Number of observed (0) and expected (E) cases, rate ratios* (RRs) with upper and lower 95\% Cls for pneumococcal disease (including pneumonia, septicaemia and meningitis) in people with selected mental disorders compared with the reference cohort $†$

\begin{tabular}{|c|c|c|c|c|c|c|c|c|c|c|c|c|c|}
\hline \multirow[b]{2}{*}{ Diagnosis } & \multirow[b]{2}{*}{ Dataset } & \multicolumn{4}{|c|}{$\begin{array}{l}\text { Lobar pneumonia and pneumococcal } \\
\text { disease, combined }\end{array}$} & \multicolumn{4}{|c|}{ Lobar pneumonia } & \multicolumn{4}{|c|}{ Pneumococcal pneumonia } \\
\hline & & 0 & E & $\mathbf{R R}$ & $95 \% \mathrm{Cl}$ & 0 & $\mathrm{E}$ & $\mathbf{R R}$ & $95 \% \mathrm{Cl}$ & 0 & $\mathrm{E}$ & RR & $95 \% \mathrm{Cl}$ \\
\hline \multirow[t]{3}{*}{ Schizophrenia } & LHES & 1922 & 827.7 & 2.3 & 2.2 to 2.4 & 1859 & 791.8 & 2.4 & 2.3 to 2.5 & 75 & 36.5 & 2.1 & 1.6 to 2.6 \\
\hline & ORLS2 & 67 & 27.1 & 2.5 & 1.9 to 3.2 & 66 & 26.1 & 2.6 & 2.0 to 3.3 & $\ddagger$ & & & \\
\hline & ORLS1 & 50 & 30.9 & 1.6 & 1.2 to 2.2 & 48 & 29.0 & 1.7 & 1.2 to 2.2 & $\ddagger$ & & & \\
\hline \multirow[t]{3}{*}{ Bipolar disorder } & LHES & 2811 & 1259.9 & 2.3 & 2.2 to 2.3 & 2729 & 1217.9 & 2.3 & 2.2 to 2.4 & 97 & 45.4 & 2.2 & 1.8 to 2.6 \\
\hline & ORLS2 & 94 & 42.7 & 2.2 & 1.8 to 2.7 & 91 & 41.4 & 2.2 & 1.8 to 2.7 & $\ddagger$ & & & \\
\hline & ORLS1 & 84 & 59.2 & 1.4 & 1.1 to 1.8 & 82 & 56.6 & 1.5 & 1.2 to 1.8 & $\ddagger$ & & & \\
\hline \multirow[t]{3}{*}{ Depression } & LHES & 4973 & 2444.5 & 2.1 & 2.0 to 2.1 & 4845 & 2369.8 & 2.1 & 2.0 to 2.1 & 158 & 78.7 & 2.1 & 1.7 to 2.4 \\
\hline & ORLS2 & 229 & 117.2 & 2.0 & 1.7 to 2.3 & 226 & 114.0 & 2.0 & 1.8 to 2.3 & 9 & 3.3 & 2.9 & 1.3 to 5.6 \\
\hline & ORLS1 & 174 & 121.8 & 1.5 & 1.2 to 1.7 & 165 & 115.3 & 1.5 & 1.2 to 1.7 & 7 & 3.1 & 2.3 & 0.9 to 4.9 \\
\hline \multirow[t]{3}{*}{ Anxiety } & LHES & 2122 & 997.0 & 2.2 & 2.1 to 2.2 & 2069 & 969.3 & 2.2 & 2.1 to 2.3 & 74 & 31.2 & 2.4 & 1.9 to 3.0 \\
\hline & ORLS2 & 61 & 29.2 & 2.1 & 1.6 to 2.7 & 61 & 28.3 & 2.2 & 1.7 to 2.8 & $\ddagger$ & & & \\
\hline & ORLS1 & 129 & 92.0 & 1.4 & 1.2 to 1.7 & 123 & 86.7 & 1.4 & 1.2 to 1.7 & $\ddagger$ & & & \\
\hline
\end{tabular}

The numbers in the columns for lobar pneumonia and for pneumococcal pneumonia exceed those in the column for 'pneumococcal disease, combined' because some people had a diagnosis of each of the first two conditions on different occasions; and because the 'pneumococcal disease, combined' totals also include cases of pneumococcal septicaemia and meningitis.

*Adjusted for sex, age in 5-year bands, time period in single calendar years in the ORLS1 and LHES datasets, and also adjusted for district of residence in ORLS1 and ORLS2, and for region of residence and deprivation score associated with patient's area of residence, in quintiles, in the LHES dataset.

tConditions used in reference cohort, with Office of Population, Censuses and Surveys (OPCS) code edition 4 for operations and International Classification of Diseases, 10th revision (ICD-10) code for diagnosis (with equivalent codes used for other coding editions): adenoidectomy (OPCS4 E20), appendectomy (H01-H03), dilation and curettage (Q10-Q11), hip replacement (W37-W39), knee replacement (W40-W42), squint (ICD10 H49-H51), cataract (H25), varicose veins (I83), haemorrhoids (I84), deflected septum (J34.2), nasal polyp (J33), impacted tooth and other disorders of teeth (K00-K03), inguinal hernia (K40), in-growing nail, toenail and other diseases of nails (L60), bunion (M20.1), internal derangement of knee (M23), dislocations, sprains and strains (S03, S13, S23, S33, S43, S53, S63, S73, S83, S93), head injury (S06 excluded from analysis of meningitis), selected limb fractures (S42, S52, S62, S82, S92), superficial injury and contusion (S00, S10, S20, S30, S40, S50, S60, S70, S80, S90), contraceptive management (Z30).

‡Data not shown for pneumonia and pneumococcal disease with non-significant results and five or fewer observed cases.

LHES, linked Hospital Episode Statistics and mortality statistics; ORLS, Oxford Record Linkage Study. 
Table 3 Number of observed (0) and expected (E) cases, rate ratios* (RRs) with upper and lower 95\% Cls for pneumococcal disease (including pneumonia, septicaemia and meningitis) in people aged under 60 years with selected mental disorders, compared with the reference cohort $\dagger$

\begin{tabular}{|c|c|c|c|c|c|c|c|c|c|c|c|c|c|}
\hline \multirow[b]{2}{*}{ Diagnosis } & \multirow[b]{2}{*}{ Dataset } & \multicolumn{4}{|c|}{$\begin{array}{l}\text { Lobar pneumonia and pneumococcal } \\
\text { disease, combined }\end{array}$} & \multicolumn{4}{|c|}{ Lobar pneumonia } & \multicolumn{4}{|c|}{ Pneumococcal pneumonia } \\
\hline & & 0 & $\mathrm{E}$ & RR & $95 \% \mathrm{Cl}$ & 0 & $\mathrm{E}$ & $\mathbf{R R}$ & $95 \% \mathrm{Cl}$ & 0 & E & RR & $95 \% \mathrm{Cl}$ \\
\hline \multirow[t]{3}{*}{ Schizophrenia } & LHES & 1144 & 420.1 & 2.8 & 2.6 to 3.0 & 1092 & 395.0 & 2.9 & 2.7 to 3.0 & 60 & 24.7 & 2.5 & 1.9 to 3.2 \\
\hline & ORLS2 & 40 & 15.0 & 2.7 & 1.9 to 3.7 & 39 & 14.3 & 2.8 & 2.0 to 3.9 & $\ddagger$ & & & \\
\hline & ORLS1 & 25 & 19.2 & 1.3 & 0.8 to 1.9 & 24 & 17.7 & 1.4 & 0.9 to 2.0 & $\ddagger$ & & & \\
\hline \multirow[t]{3}{*}{ Bipolar disorder } & LHES & 968 & 378.2 & 2.6 & 2.5 to 2.8 & 931 & 357.5 & 2.7 & 2.5 to 2.9 & 42 & 20.4 & 2.1 & 1.5 to 2.8 \\
\hline & ORLS2 & 33 & 14.0 & 2.4 & 1.6 to 3.4 & 32 & 13.3 & 2.4 & 1.7 to 3.5 & $\ddagger$ & & & \\
\hline & ORLS1 & 39 & 21.3 & 1.9 & 1.3 to 2.6 & 39 & 20.2 & 2.0 & 1.4 to 2.7 & $\ddagger$ & & & \\
\hline \multirow[t]{3}{*}{ Depression } & LHES & 1431 & 513.4 & 2.9 & 2.8 to 3.1 & 1360 & 484.2 & 2.9 & 2.8 to 3.1 & 70 & 27.9 & 2.6 & 2.0 to 3.3 \\
\hline & ORLS2 & 77 & 26.8 & 3.0 & 2.4 to 3.8 & 74 & 25.6 & 3.0 & 2.4 to 3.8 & 7 & 1.2 & 6.6 & 2.5 to 14.8 \\
\hline & ORLS1 & 73 & 51.7 & 1.4 & 1.1 to 1.8 & 51 & 33.8 & 1.5 & 1.1 to 2.0 & $\ddagger$ & & & \\
\hline \multirow[t]{3}{*}{ Anxiety } & LHES & 516 & 187.3 & 2.8 & 2.6 to 3.1 & 498 & 177.5 & 2.8 & 2.6 to 3.1 & 25 & 9.7 & 2.6 & 1.7 to 3.9 \\
\hline & ORLS2 & 19 & 5.5 & 3.5 & 2.1 to 5.5 & 19 & 5.3 & 3.7 & 2.2 to 5.8 & $\ddagger$ & & & \\
\hline & ORLS1 & 65 & 48.7 & 1.4 & 1.0 to 1.7 & 51 & 45.2 & 1.4 & 1.0 to 1.8 & $\ddagger$ & & & \\
\hline
\end{tabular}

The numbers in the columns for lobar pneumonia and for pneumococcal pneumonia exceed those in the column for 'pneumococcal disease, combined' because some people had a diagnosis of each of the first two conditions on different occasions; and because the 'pneumococcal disease, combined' totals also include cases of pneumococcal septicaemia and meningitis.

${ }^{*}$ Adjusted for sex, age in 5-year bands, time period in single calendar years in the ORLS1 and LHES datasets, and also adjusted for district of residence in ORLS1 and ORLS2, and for region of residence and deprivation score associated with patient's area of residence, in quintiles, in the LHES dataset.

tConditions used in reference cohort, with Office of Population, Censuses and Surveys (OPCS) code edition 4 for operations and International Classification of Diseases, 10th revision (ICD10) code for diagnosis (with equivalent codes used for other coding editions): adenoidectomy (OPCS4 E20), appendectomy (H01-H03), dilation and curettage (Q10-Q11), hip replacement (W37-W39), knee replacement (W40-W42), squint (ICD10 H49-H51), cataract (H25), varicose veins (I83), haemorrhoids (I84), deflected septum (J34.2), nasal polyp (J33), impacted tooth and other disorders of teeth (K00-K03), inguinal hernia (K40), in-growing nail, toenail and other diseases of nails (L60), bunion (M20.1), internal derangement of knee

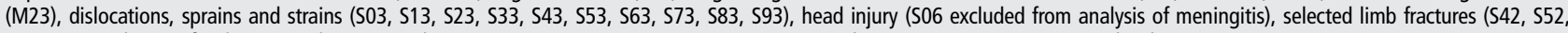
$\mathrm{S62}, \mathrm{S} 82, \mathrm{S92})$, superficial injury and contusion (S00, S10, S20, S30, S40, S50, S60, S70, S80, S90), contraceptive management (Z30).

$\ddagger$ Data not shown for pneumonia and pneumococcal disease with non-significant results and five or fewer observed cases.

LHES, linked Hospital Episode Statistics and mortality statistics; ORLS, Oxford Record Linkage Study.

All analyses were repeated excluding cases of pneumonia and pneumococcal disease that occurred within the first year of hospitalisation for each of the psychiatric disorders (see online appendix). The results were almost unchanged: for example, in the England dataset, the RR for pneumonia and pneumococcal disease in people with schizophrenia excluding cases in the first year was 2.3 (95\% CI 2.2 to 2.5 ), similar to the RR overall $(\mathrm{RR}=2.3)$ (online appendix and Table 2). Thus, the increased risk of pneumococcal infection was not just a risk of having been in hospital recently with a psychiatric disorder.

To assess the risk of pneumococcal infection in people with mental disorders in the context of diseases that are well known to be associated with a high risk of infection, we undertook the same analysis as described in the Methods section to estimate risks in patients with chronic obstructive pulmonary disease (COPD) and diabetes mellitus (DM). The risk of pneumococcal disease associated with COPD was 4.0 (95\% CI 4.0 to 4.1$)$ in the English dataset and 3.6 (95\% CI 3.3 to 3.9) in ORLS1. The risk of pneumococcal disease associated with DM was 2.1 (95\% CI 2.0 to $2.2)$ in the England dataset and 1.9 (95\% CI 1.6 to 2.2) in ORLS1.

\section{Absolute risk}

We can only calculate absolute risk approximately because we do not have data on migration. The number of people in the schizophrenia cohort in England was 85769 , and of those, $1922(2.2 \%)$ had a hospital admission for pneumococcal disease. The equivalent percentages for people with bipolar disorder, depression or anxiety were 3.3\% (2811/83 951), 3.6\% $(4973 / 138963)$ and $3.6 \%(2122 / 58816)$, respectively. In those under 60 years old, the approximate absolute risk of hospitalisation for pneumococcal disease was $1.6 \%(1144 / 73080)$ in the schizophrenia cohort, $1.7 \%(968 / 57405)$ in those with bipolar disorder, $1.6 \%(1431 / 86937)$ in those with depression and
$1.5 \%(516 / 34118)$ in those with anxiety. These are incomplete enumerations of lifetime risk as they include only a mean follow-up of approximately 6 years.

\section{DISCUSSION}

\section{Principal findings}

People admitted to hospital for schizophrenia, bipolar disorder, depression or anxiety had an increased risk of subsequent pneumococcal disease. The RR was higher in people younger than 60 years than in others. The risk was associated with the psychiatric disorder rather than with the event of hospitalisation: it remained high for years after discharge. It seems unlikely that the mechanism of the association is specific to any biological characteristics of the disorders studied, particularly as similarly high RRs were found in all four mental conditions.

Pneumococcal vaccine is now offered routinely to people aged 65 and over in England. Accordingly, we thought that we might find a lower risk in the ORLS2 and England datasets than in the earlier period of ORLS1. We did not; RRs were actually higher, rather than lower, in the later cohorts. We cannot account for the difference between the periods, but admission rates for psychiatric care were much lower in recent years than they were in the period covered by ORLS1. It is likely that patients in the recent era who are admitted for psychiatric care are more severely ill or less able to care for themselves than those in earlier times.

\section{Speculative mechanisms of association}

Unhealthy lifestyle, lack of self-care, physical circumstances including poor housing and homelessness, and health-risk activities are common in people with mental illness, and these are associated with adverse health outcomes. ${ }^{12-14}$ Compared with the general population, the prevalence of smoking, ${ }^{15} 16$ alcohol $^{17}$ and 
substance abuse, ${ }^{18}$ which are known risk factors for lung infections, ${ }^{19} 20$ are higher in patients with mental disorders than in the general population. Whether independently or in combination, these factors are likely to increase the risk of pneumococcal disease. We had no data on smoking, but other studies have shown that the risk of respiratory infection was high in people with mental disorders even after controlling for smoking. ${ }^{1} 1$

The effect of psychiatric conditions, especially active psychosis, on cognitive function may compromise patients' ability to adequately recognise health problems, to actively look for help, and to communicate effectively with care providers. ${ }^{13} \quad 22 \quad 23$ Altered perception of pain and atypical presentation of painrelated symptoms are widely reported in people with severe mental diseases, affecting their healthcare-seeking behaviour and clinical presentation. ${ }^{24} 25$ If pain thresholds are high in people with psychiatric conditions, the earlier and milder symptoms of pneumococcal infection, such as chest pain or headache, might not be recognised by the patient until the infection progresses. Patients with mental illness may require continuous treatment with antipsychotics, some of which are known to have side effects that include a reduction of white blood cells and worsened respiratory muscle functioning. ${ }^{26-29}$ These factors, too, may increase the risk of infection, including pneumonia. It is also possible that staff caring for patients with severe mental illness may not always readily recognise symptoms and signs of physical illness.

\section{Strengths and limitations}

The strengths include the use of a large, current, nationwide population-based dataset and of a historical 'baseline' for pneumococcal infection in the ORLS1.

We were wholly dependent on the reliability of coded diagnostic data in the datasets. Most of the cases of pneumococcal disease were coded as lobar pneumonia. Until the most recent revision, the ICD classification regarded lobar pneumonia and pneumococcal pneumonia as synonymous and they had the same code. We had to accept this and, even after 2001 when they became distinguishable by code, lobar pneumonia was a much more common diagnosis than pneumococcal pneumonia. In fact, the RRs for lobar and pneumococcal pneumonia were very similar. Further, although the numbers were small, the risks of pneumococcal septicaemia and meningitis (unlikely to be misdiagnosed) were also elevated.

We had no data on pneumococcal vaccination, laboratory confirmation of pneumococcal infection or pathology reports, microbiological information on serotypes, information on prescribed treatment or antibiotic sensitivity. The study population was limited to people who had a record of hospital admission or day care for the mental disorders and may not necessarily apply to people with mental disorders that are less severe.

Our estimates of the absolute risk of pneumococcal disease are approximate. They do not take account of population migration, or of cases of pneumococcal infection treated outside hospital. Nonetheless, the estimated absolute risk of $2.2 \%$ in the schizophrenia cohort and above 3\% in the other three groups of patients with mental disorders indicates that pneumococcal disease is a common enough risk for immunisation to be considered.

\section{Implications of the study}

Our findings should be regarded as hypothesis generating rather than definitive. They need confirmation or refutation. If confirmed, national guidance on pneumococcal vaccination might need revision to include people with severe mental disorders.
The level of risk of pneumococcal disease in people with severe mental illness, at about a twofold excess, is similar to that for pneumococcal disease in people with diabetes (for which immunisation is generally recommended). If the high-risk group is mainly those with severe enough mental illness to warrant hospitalisation for psychiatric care, opportunistic immunisation of these patients while in hospital could be part of the policy.

In recent years people aged 65 years and over in the general population in England have routinely been offered immunisation against the pneumococcus. If people with severe mental illness had been protected either directly, or by an increase in herd immunity in the general population resulting from routine pneumococcal immunisation, a decline in the relative risk of pneumococcal disease in our study might have been expected. We did not find a decline. However, there are questions about the effectiveness of the vaccine used in the UK (Pneumovax, PPV-23) in preventing pneumonia. Reports on effectiveness of pneumococcal vaccine PPV-23 in adults are inconclusive and consideration should be given to conjugate vaccines, with greater efficacy in preventing pneumonia and other invasive forms of pneumococcal disease in high-risk groups. ${ }^{30} 31$

\section{Unanswered questions}

Although people with mental disorders have an increased risk of pneumococcal disease, it is not known whether they would benefit from pneumococcal immunisation. There is a chance that the association reported by us might be mediated by confounders or other factors that would not be affected by immunisation. One possible approach to taking this work forward would be to undertake a randomised controlled trial of pneumococcal vaccine in people with severe mental illness.

Acknowledgements David Yeates wrote the software package used for the analysis. Over many years, the linked data files were built by Leicester Gill and Matt Davidson, Unit of Health-Care Epidemiology, University of Oxford. Olena Seminog's contribution was done in part as a research placement for the MSc in Global Health Science, University of Oxford.

Contributors MJG and OS designed the study. OS did the analysis. OS wrote the initial draft. Both authors contributed to the drafting of the manuscript, and approved the final manuscript.

Funding The Unit of Health-Care Epidemiology is funded by the English National Institute for Health Research to analyse the linked data (grant number RNC/035/002).

Disclaimer The views expressed in this paper do not necessarily reflect those of the funding body.

Competing interests None.

Ethical approval Ethical approval for analysis of the record linkage study data was obtained from the Central and South Bristol Multi-Centre Research Ethics Committee (04/Q2006/176).

Provenance and peer review Not commissioned; internally peer reviewed.

\section{REFERENCES}

1 Copeland LA, Mortensen EM, Zeber JE, et al. Pulmonary disease among inpatient decedents: impact of schizophrenia. Prog Neuropsychopharmacol Biol Psychiatry 2007;31:720-6

2 Lynch JP III, Zhanel GG. Streptococcus pneumoniae: epidemiology and risk factors, evolution of antimicrobial resistance, and impact of vaccines. Curr Opin Pulm Med 2010;16:217-25.

3 Reynolds JH, McDonald G, Alton $\mathrm{H}$, et al. Pneumonia in the immunocompetent patient. Br J Radiol 2010;83:998-1009.

4 Koedel U, Scheld WM, Pfister HW. Pathogenesis and pathophysiology of pneumococcal meningitis. Lancet Infect Dis 2002;2:721-36.

5 Department of Health. Chapter 25. Pneumococcal. immunisation against infectious disease 2006. In: The Green Book. London: Department of Health, 2010. http:// webarchive.nationalarchives.gov.uk/+/www.dh.gov.uk/prod_consum_dh/groups/ dh_digitalassets/@dh/@en/documents/digitalasset/dh_122639.pdf (accessed 14 Jun 2012) 
6 Centers for Disease Control and Prevention. Updated Recommendations for Prevention of Invasive Pneumococcal Disease Among Adults Using the 23-Valent Pneumococcal Polysaccharide Vaccine (PPSV23). Atlanta, Georgia: Centers for Disease Control and Prevention, 2010. http://www.cdc.gov/mmwr/preview/ mmwrhtml/mm5934a3.htm (accessed 14 Jun 2012).

7 Gill L, Goldacre M, Simmons $\mathrm{H}$, et al. Computerised linking of medical records: methodological guidelines. J Epidemiol Community Health 1993;47:316-19.

8 Goldacre M, Kurina L, Yeates $D$, et al. Use of large medical databases to study associations between diseases. QJM 2000;93:669-75.

9 Melegaro A, Edmunds WJ, Pebody R, et al. The current burden of pneumococcal disease in England and Wales. J Infect 2006;52:37-48.

10 Goldacre MJ, Wotton CJ, Yeates D, et al. Cancer in people with depression or anxiety: record-linkage study. Soc Psychiatry Psychiatr Epidemiol 2007;42:683-9.

11 Breslow N, Day N. Statistical Methods in Cancer Research. Vol II. The Design and Analysis of Cohort Studies. Lyon: International Agency for Research on Cancer, 1987: 93-5.

12 Goff DC, Cather C, Evins AE, et al. Medical morbidity and mortality in schizophrenia: guidelines for psychiatrists. J Clin Psychiatry 2005;66:183-94.

13 Brown S, Mitchell C. Predictors of death from natural causes in schizophrenia: 10-year follow-up of a community cohort. Soc Psychiatry Psychiatr Epidemiol 2012;47:843-7.

14 Martens WH. A review of physical and mental health in homeless persons. Public Health Rev 2001:29:13-33.

15 Ziedonis D, Hitsman B, Beckham JC, et al. Tobacco use and cessation in psychiatric disorders: National Institute of Mental Health report. Nicotine Tob Res 2008:10:1691-715.

16 Lawrence D, Mitrou F, Zubrick SR. Smoking and mental illness: results from population surveys in Australia and the United States. BMC Public Health 2009;9:285.

17 Regier DA, Farmer ME, Rae DS, et al. Comorbidity of mental disorders with alcohol and other drug abuse. JAMA 1990;264:2511-18.

18 Compton WM, Thomas YF, Stinson FS, et al. Prevalence, correlates, disability, and comorbidity of DSM-IV drug abuse and dependence in the United States: results from the national epidemiologic survey on alcohol and related conditions. Arch Gen Psychiatry 2007;64:566-76.

19 Almirall J, González CA, Balanzó X, et al. Proportion of community-acquired pneumonia cases attributable to tobacco smoking. Chest 1999;116:375-9.

20 Raasch CE, Zhang P, Siggins RW II, et al. Acute alcohol intoxication impairs the hematopoietic precursor cell response to pneumococcal pneumonia. Alcohol Clin Exp Res 2010;34:2035-43.

21 Sokal J, Messias E, Dickerson FB, et al. Comorbidity of medical illnesses among adults with serious mental illness who are receiving community psychiatric services. J Nerv Ment Dis 2004:192:421-7.

22 Pedrelli P, McQuaid JR, Granholm E, et al. Measuring cognitive insight in middle-aged and older patients with psychotic disorders. Schizophr Res 2004;71:297-305

23 Chen $\mathrm{YH}_{\text {, Lin }} \mathrm{HC}$, Lin HC. Poor clinical outcomes among pneumonia patients with schizophrenia. Schizophr Bull 2011;37:1088-94.

24 Murakami H, Tamasawa N, Yamashita $\mathrm{M}$, et al. Altered pain perception in schizophrenia. Lancet 2010;375:864.

25 Rosenthal SH, Porter KA, Coffey B. Pain insensitivity in schizophrenia. Case report and review of the literature. Gen Hosp Psychiatry 1990;12:319-22.

26 Atkin K, Kendall F, Gould D, et al. Neutropenia and agranulocytosis in patients receiving clozapine in the UK and Ireland. $\mathrm{Br} J$ Psychiatry 1996;169:483-8.

27 Oyesanmi 0 , Kunkel EJ, Monti DA, et al. Hematologic side effects of psychotropics. Psychosomatics 1999;40:414-21.

28 Demler TL, Trigoboff E. Are clozapine blood dyscrasias associated with concomitant medications? Innov Clin Neurosci 2011;8:35-41.

29 Wilcox PG, Bassett $A$, Jones $B$, et al. Respiratory dysrhythmias in patients with tardive dyskinesia. Chest 1994;105:203-7.

30 Moberley SA, Holden J, Tatham DP, et al. Vaccines for preventing pneumococcal infection in adults. Cochrane Database Syst Rev 2008;(1):CD000422.

31 Huss $A$, Scott $P$, Stuck $A E$, et al. Efficacy of pneumococcal vaccination in adults: a meta-analysis. CMAJ 2009;180:48-58. 